\title{
Enterprise Architecture dengan Pendekatan TOGAF untuk Transformasi Digital pada UMKM
}

\author{
(Studi Kasus: UMKM Makanan Oleh-Oleh)
}

\author{
Ivana Tyora Oktavian \\ Fakultas Rekayasa Industri, Jurusan Sistem Informasi \\ Universitas Telkom \\ Jl. Telekomunikasi No.1, Bandung \\ ivanatyora@student.telkomuniversity.ac.id
}

Asti Amalia Nur Fajrillah

Fakultas Rekayasa Industri, Jurusan Sistem Informasi Universitas Telkom

Jl. Telekomunikasi No.1, Bandung astiamalia@telkomuniversity.ac.id

\author{
Irfan Darmawan \\ Fakultas Rekayasa Industri, Jurusan Sistem Informasi \\ Universitas Telkom \\ Jl. Telekomunikasi No.1, Bandung \\ irfandarmawan@telkomuniversity.ac.id
}

\begin{abstract}
Abstrak - Berlakunya pasar bebas di Indonesia mengakibatkan semakin ketatnya persaingan dalam industri bisnis. Hal ini mendorong pelaku bisnis khususnya UMKM untuk melakukan transformasi digital melalui perubahan dalam hal mengakses dan mendistribusikan informasi yang awalnya manual menjadi digital. Adanya transformasi digital akan meningkatkan operasional bisnis menjadi lebih efisien, memberikan peluang bisnis yang baru dan menghasilkan keuntungan yang besar bagi UMKM. Namun belum semua UMKM dapat melakukan transformasi digital. Hal ini disebabkan oleh beberapa permasalahan yang ada di UMKM seperti: belum meratanya tingkat penjualan di Indonesia, belum adanya kesiapan dalam membuka pasar yang baru, produk belum sepenuhnya dikenal oleh masyarakat, belum adanya kesiapan yang matang atas produk, belum mampu mengelola permintaan yang besar, dan pengelolaan feedback yang belum optimal. Permasalahan tersebut mengakibatkan adanya tantangan tersendiri bagi UMKM untuk mencapai visi UMKM. Oleh karena itu, dalam mencapai visinya diperlukan transformasi digital melalui Enterprise Architecture (EA) dimana EA akan menyelaraskan sisi bisnis UMKM dan IT. Dalam perancangan EA pada UMKM digunakan frawework TOGAF. Perancangan EA ini menghasilkan sebuah blueprint company specific yang dapat digunakan sebagai acuan untuk pengembangan sistem informasi pada UMKM sejenis berupa UMKM tipe menengah dengan bisnis Makanan Oleh-Oleh.
\end{abstract}

Kata kunci - UMKM; Transformasi Digital; Enterprise Architecture; TOGAF

\section{PENDAHULUAN}

Dewasa ini, Dengan diberlakukannya pasar bebas di Indonesia mengakibatkan persaingan dalam industri bisnis yang semakin ketat. Hal ini mendorong pelaku bisnis khususnya UMKM untuk melakukan sebuah transformasi digital. Transformasi merupakan sebuah pergeseran yang struktural, secara bertahap, menyeluruh, dan tidak dapat dikembalikan ke bentuk semula (irreversible). Transformasi digital ditandai dengan adanya perkembangan jaringan yang luas, pergeseran cara komunikasi, serta perubahan gaya hidup masyarakat. Menurut data Internet World Stat (2012), negara dengan pengguna internet terbanyak di asia urutan nomor empat yaitu Indonesia. Saat ini ada sekitar 55 juta penduduk Indonesia yang menggunakan internet dan terhubung dengan media berbasis teknologi informasi dan komunikasi. Hal ini menjadikan Teknologi Informasi Komunikasi mempunyai peranan penting dalam mewujudkan transformasi digital tidak dapat dipandang sebelah mata [1]. Adanya transformasi digital mengakibatkan operasional bisnis UMKM yang lebih efisien, memberikan peluang bisnis yang baru serta menghasilkan keuntungan yang lebih besar bagi UMKM [2].

Namun dalam penerapan transformasi digital tidaklah mudah. Hal-hal yang menjadi kendala dalam penerapan transformasi digital antara lain terkait dengan faktor manusia, kurangnya sumber daya yang memadai, kurangnya strategi bisnis yang jelas, serta proses bisnis yang tidak berfokus pada kebutuhan pelanggan. Oleh karena itu, diperlukan adanya Enterprise Architecture yang menyelaraskan bisnis dengan IT [3]. Enterprise Architecture adalah satu praktek manajemen untuk memaksimalkan kontribusi dari sumber daya perusahaan, 
investasi TI, dan aktivitas pembangunan sistem untuk mencapai tujuan kinerjanya [4][5][6].

Salah satu kerangka praktik untuk mengembangkan Enterprise Architecture pada UMKM yaitu TOGAF (The Open Group Architecture Framework), yang dikembangkan oleh The Open Group [7]. TOGAF bersifat open source dimana dapat di modifikasi sesuai kebutuhan UMKM [8]. Untuk perancangan EA menggunakan TOGAF dimulai dari fase preliminary hingga fase technology architecture. Perancangan EA ini menghasilkan blueprint company specific yang dapat digunakan sebagai acuan UMKM Makanan Oleh-oleh untuk mencapai transformasi digital.

\section{METODE}

Metode yang digunakan yaitu metodologi TOGAF ADM yang dikeluarkan oleh framework TOGAF. Sebelum memasuki fase-fase dalam TOGAF ADM maka perlu dilakukan pengelompokkan UMKM berdasarkan jenisnya [8].

\subsection{Klasifikasi UMKM}

Klasifikasi UMKM digunakan untuk mengetahui level kebutuhan UMKM untuk mencapai transformasi digital. Klasifikasi UMKM dilakukan berdasarkan aset UMKM dan pendapatan UMKM [9].

\subsection{TOGAF ADM}

TOGAF ADM merupakan hasil dari kontribusi secara berkelanjutan dari praktisi arsitektur yang mendeskripsikan sebuah metode pengembangan dan penyusunan lifecyle dari suatu EA. Terdapat empat domain pada TOGAF ADM yaitu bisnis, data, aplikasi dan teknologi. Terdapat beberapa fase di TOGAF ADM namun yang peneliti gunakan hanya fase preliminary, architecture vision (fase A), business architecture (fase $\mathrm{B}$ ), information system architecture (fase C), dan technology architecture (fase D).

\section{HASIL DAN DISKUSI}

\subsection{Klasifikasi Usaha Mikro Kecil dan Menengah}

Karakteristik pada UMKM merupakan sifat yang melekat pada aktivitas usaha maupun perilaku pengusaha pada saat menjalankan bisnisnya. Berdasarkan karakteristik yang ada pada UU Nomor 20 Tahun 2008, UMKM Kylafood temasuk kedalam Usaha Menengah, dengan kriteria seperti pada TABEL 1.

TABEL 1 Klasifikasi UMKM

\begin{tabular}{|c|l|l|l|}
\hline \multirow{2}{*}{ Usaha } & \multicolumn{2}{|c|}{ Kriteria } & \multicolumn{2}{c|}{ Deskripsi } \\
\cline { 2 - 3 } & \multicolumn{1}{|c|}{ Omset } & \multicolumn{1}{|c|}{ Aset } \\
\hline Kylafood & $\begin{array}{l}\text { Rp.500 } \\
\text { juta }<\text { Aset } \\
<\text { Rp.100 } \\
\text { miliar } \\
\text { (dalam }\end{array}$ & $\begin{array}{l}\text { Rp.2.5 } \\
\text { milyar } \\
<\text { Omset } \\
\text { Rp.50 } \\
\text { satu tahun) } \\
\text { miliar } \\
\text { (dalam satu } \\
\text { tahun) }\end{array}$ & $\begin{array}{l}\text { Kylafood memiliki aset } \\
\text { Rp502.000.000. Kemudian untuk } \\
1 \text { hari UMKM Kylafood dapat } \\
\text { menjual sekitar 600 produk dan } \\
\text { penghasilan perbulan } \\
\text { Rp300.000.000. }\end{array}$ \\
\hline
\end{tabular}

\subsection{Perancangan Enterprise Architecture}

Perancangan Enterprise Architecture pada UMKM Makanan Oleh-Oleh dilakukan dengan menggunakan TOGAF ADM dari preliminary phase hingga technology architecture phase.

1) Preliminary Phase

Tahap ini merupakan tahap awal perancangan EA pada TOGAF ADM. Tahap ini menjelaskan persiapan atau inisiasi perancangan EA menggunakan TOGAF ADM yang mendukung kebutuhan bisnis untuk digunakan dalam arsitektur target. Pada tahap ini dibuat artefak principle catalog yang merupakan prinsipprinsip yang dibutuhkan untuk pengembangan fase business architecture, data architecture, aplication architecture, dan technology architecture. TABEL 2 dibawah ini merupakan principle catalog UMKM Makanan Oleh-Oleh.

TABEL 2a Principle Catalog Business Architecture

\begin{tabular}{|c|c|c|}
\hline Arsitektur & Prinsip & Deskripsi \\
\hline \multirow[t]{5}{*}{$\begin{array}{c}\text { Business } \\
\text { Architecture }\end{array}$} & $\begin{array}{l}\text { Keberlangsungan } \\
\text { bisnis }\end{array}$ & $\begin{array}{ll}\text { Keberlangsungan } & \text { kegiatan } \\
\text { operasional bisnis pada } & \text { UMKM } \\
\text { tetap berjalan meskipun } & \text { terdapat } \\
\text { beberapa kendala. } & \end{array}$ \\
\hline & $\begin{array}{l}\text { Penyempurnaan } \\
\text { produk }\end{array}$ & $\begin{array}{l}\text { Melakukan penyempurnaan produk } \\
\text { dan diversifikasi produk sesuai } \\
\text { minat konsumen dan melihat } \\
\text { keadaan pasar. }\end{array}$ \\
\hline & Kualitas produk & $\begin{array}{l}\text { Meningkatkan kualitas produk } \\
\text { dengan melakukan pemilihan bahan } \\
\text { baku yang terbaik dari vendor, } \\
\text { melakukan produksi produk sesuai } \\
\text { dengan standard yang ada, dan } \\
\text { memastikan alat produksi berfungsi } \\
\text { dengan baik. }\end{array}$ \\
\hline & $\begin{array}{l}\text { Kompetensi SDM } \\
\text { yang bermutu }\end{array}$ & $\begin{array}{l}\text { Menyelenggarakan pelatihan untuk } \\
\text { pegawai terkait produksi produk } \\
\text { untuk meningkatkan kualitas SDM } \\
\text { UMKM Kylafood. }\end{array}$ \\
\hline & $\begin{array}{c}\text { Pertanggungjawaban } \\
\text { distribusi }\end{array}$ & $\begin{array}{l}\text { Mempertanggungjawabkan agar } \\
\text { produk terdistribusi dengan baik } \\
\text { dan tepat waktu kepada reseller dan } \\
\text { konsumen. }\end{array}$ \\
\hline
\end{tabular}

TABEL 2b Principle Catalog Data Architecture

\begin{tabular}{|c|c|c|}
\hline Arsitektur & Prinsip & Deskripsi \\
\hline \multirow[t]{5}{*}{$\begin{array}{c}\text { Data } \\
\text { Architecture }\end{array}$} & Aset Data & $\begin{array}{l}\text { Data merupakan aset yang memiliki nilai } \\
\text { untuk UMKM dan harus dikelola dan } \\
\text { dijaga dengan baik. }\end{array}$ \\
\hline & $\begin{array}{c}\text { Data dapat di } \\
\text { akses }\end{array}$ & $\begin{array}{l}\text { Data dapat diakses dengan mudah oleh } \\
\text { pengguna sesuai dengan otoritas yang } \\
\text { ada. }\end{array}$ \\
\hline & Akurasi data & $\begin{array}{l}\text { Data harus dapat dipertanggungjawabkan } \\
\text { kebenarannya. }\end{array}$ \\
\hline & Integrasi data & $\begin{array}{l}\text { Data yang dimiliki UMKM dapat } \\
\text { terhubung antar pengguna untuk } \\
\text { menunjang bisnisnya dan menghindari } \\
\text { adanya redudansi data. }\end{array}$ \\
\hline & $\begin{array}{c}\text { Keamanan } \\
\text { data }\end{array}$ & $\begin{array}{l}\text { Data yang dimiliki oleh UMKM harus } \\
\text { dijaga dan dilindungi dari serangan } \\
\text { maupun pencurian data yang } \\
\text { memungkinkan data dieksploitasi oleh } \\
\text { pengguna yang tidak sesuai dengan } \\
\text { otoritasnya. }\end{array}$ \\
\hline
\end{tabular}


TABEL 2c Principle Catalog Application Architecture

\begin{tabular}{ccl}
\hline Arsitektur & Prinsip & \multicolumn{1}{c}{ Deskripsi } \\
\hline $\begin{array}{c}\text { Application } \\
\text { Architecture }\end{array}$ & $\begin{array}{c}\text { Usability } \\
\text { Aplikasi }\end{array}$ & $\begin{array}{l}\text { Aplikasi yang digunakan memiliki } \\
\text { fungsionalitas yang tinggi, user-friendly } \\
\text { serta pendokumentasian yang baik. }\end{array}$ \\
\cline { 2 - 3 } & $\begin{array}{c}\text { Keamanan } \\
\text { Aplikasi }\end{array}$ & $\begin{array}{l}\text { Keamanan aplikasi dibutuhkan UMKM } \\
\text { dengan menetapkan tingat otorisasi } \\
\text { pengguna. }\end{array}$ \\
\cline { 2 - 3 } & Fleksibilitas & $\begin{array}{l}\text { Tidak perlu dilakukan pengubahan } \\
\text { teknologi secara terus-menerus karena } \\
\text { aplikasi dapat berfungsi dengan adanya } \\
\text { platform yang tersedia. }\end{array}$ \\
\hline
\end{tabular}

TABEL 2d Principle Catalog Technology Architecture

\begin{tabular}{ccl}
\hline Arsitektur & Prinsip & \multicolumn{1}{c}{ Deskripsi } \\
\hline $\begin{array}{l}\text { Technology } \\
\text { Application }\end{array}$ & Keamanan Teknologi & $\begin{array}{l}\text { Teknologi yang digunakan harus } \\
\text { dijaga agar terhindar dari resiko } \\
\text { yang mungkin terjadi. }\end{array}$ \\
\cline { 2 - 4 } & Interoperabilitas & $\begin{array}{l}\text { Kemampuan teknologi untuk } \\
\text { mendukung adanya pertukaran } \\
\text { data pada setiap aktivitas. }\end{array}$ \\
\cline { 2 - 5 } & $\begin{array}{l}\text { Perubahan teknologi } \\
\text { salam mendukung operasional }\end{array}$ & $\begin{array}{l}\text { bisnis maka diperlukan } \\
\text { perubahan teknologi sesuai } \\
\text { dengan kebutuhan bisnis } \\
\text { UMKM. }\end{array}$ \\
& bisnis &
\end{tabular}

\section{2) Architecture Vision}

Fase Architecture Vision adalah fase awal dalam perancangan EA menggunakan TOGAF ADM. Fase ini akan mendefinisikan mengenai ruang lingkup, stakeholder, dan visi arsitektur. Pada fase ini menghasilkan beberapa artefak. Salah satunya yaitu value chain diagram yang digambarkan pada GAMBAR 1. Value chain diagram merupakan diagram yang mendefinisikan aktivitas-aktivitas pada UMKM yang terdiri dari aktivitas utama (primary activities) dan aktivitas pendukungnya (support activities) [10].

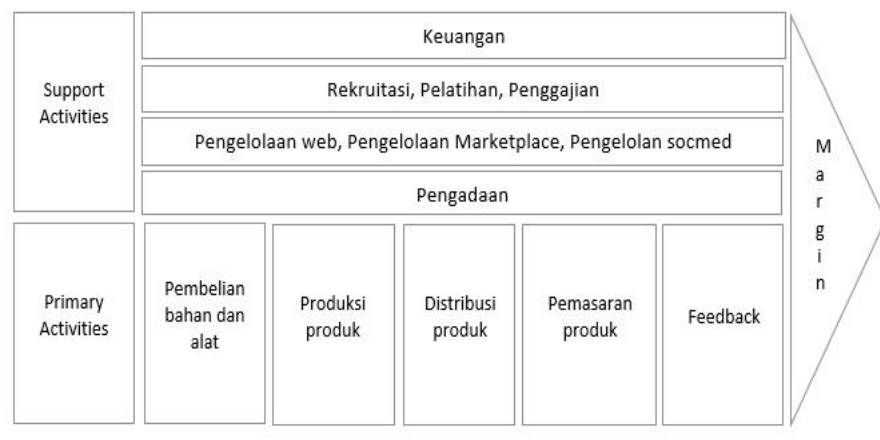

GAMBAR 1 Value chain diagram

\section{3) Business Architecture}

Business Architecture merupakan fase yang mendefinisikan kebutuhan UMKM dalam menjalankan fungsi bisnisnya untuk mencapai target. Perancangan business architecture ini akan menentukan arsitektur target yang akan dibangun untuk mencapai tujuan UMKM. Fase Business Architecture menghasilkan beberapa artefak. Salah satunya yaitu Driver / Goal /
Objective Catalog. Pada TABEL 3 adalah Driver / Goal / Objective Catalog yang menggambarkan hubungan antara driver, goals, dan objectives UMKM Makanan Oleh-Oleh.

TABEL 3a Driver / Goal / Objective Catalog I

\begin{tabular}{|c|c|c|}
\hline Driver & Goal & Objective \\
\hline \multirow{4}{*}{$\begin{array}{c}\text { Pemerataan } \\
\text { penjualan di } \\
\text { Indonesia dan } \\
\text { persiapan produk } \\
\text { untuk pasar } \\
\text { Internasional }\end{array}$} & \multirow{2}{*}{$\begin{array}{c}\text { Menciptakan } \\
\text { pemerataan tingkat } \\
\text { penjualan di Indonesia } \\
\text { dan pengenalan produk } \\
\text { baik di dalam negeri } \\
\text { maupun Internasional }\end{array}$} & $\begin{array}{l}\text { Optimalisasi media } \\
\text { penjualan }\end{array}$ \\
\hline & & $\begin{array}{c}\text { Mengetahui data } \\
\text { penjualan } \\
\text { berdasarkan kategori }\end{array}$ \\
\hline & \multirow{2}{*}{$\begin{array}{c}\text { Meningkatkan kesiapan } \\
\text { dalam membuka pasar } \\
\text { yang baru } \\
\text { (Internasional) }\end{array}$} & $\begin{array}{c}\text { Standarisasi produk } \\
\text { terpenuhi }\end{array}$ \\
\hline & & $\begin{array}{c}\text { Adanya kemudahan } \\
\text { pemilihan } \\
\text { distribution channel }\end{array}$ \\
\hline
\end{tabular}

TABEL 3b Driver / Goal / Objective Catalog II

\begin{tabular}{ccc} 
Driver & Goal & Objective \\
\hline Keuntungan yang & Mempermudah & Perlunya integrasi distribution \\
lebih besar & transaksi untuk & channel dengan website \\
\cline { 2 - 2 } mengatasi & perlunya aplikasi yang \\
peluang bisnis & mendukung untuk mengelola \\
yang baru & keuangan UMKM \\
\cline { 2 - 2 } & $\begin{array}{c}\text { Mempersiapkan } \\
\text { produk secara } \\
\text { matang }\end{array}$ & $\begin{array}{c}\text { Melakukan seleksi vendor } \\
\text { dalam memilih bahan baku }\end{array}$ \\
\hline Mampu & Perlunya aplikasi untuk \\
& mengelola & mengelola bahan baku dan \\
permintaan & stock \\
\cline { 2 - 2 } & yang besar & Menjaga jumlah stock produk \\
\hline
\end{tabular}

TABEL 3c Driver / Goal / Objective Catalog III

\begin{tabular}{ccc}
\hline Driver & Goal & Objective \\
\hline $\begin{array}{c}\text { Operasional } \\
\text { bisnis yang } \\
\text { lebih efisien }\end{array}$ & Mengevaluasi kritik & Adanya tracking terhadap \\
& konsumen & kritik dan saran yang masuk \\
& & $\begin{array}{c}\text { sehingga kritik dan saran } \\
\text { terselesaikan }\end{array}$ \\
\hline
\end{tabular}

Artefak lain yang dihasilkan pada fase business architecture adalah Business service / functional / process catalog. Catalog ini menggambarkan pemetaan dari fungsi, layanan dan proses bisnis yang ada. Pada TABEL 4 merupakan Business Service / Functional / Process Catalog pada UMKM Makanan Oleh-Oleh.

TABEL 4a Business Service / Functional / Process Catalog Produksi

\begin{tabular}{ccc}
\hline Business Function & Business Service & Business Process \\
\hline Produksi & Pembuatan produk & Pembuatan seblak \\
\cline { 2 - 2 } & & Pembuatan cilok \\
\cline { 2 - 2 } & & Pembuatan batagor \\
\cline { 2 - 2 } & & Pembuatan cireng \\
&
\end{tabular}

TABEL 4b Business Service / Functional / Process Catalog Pemasaran

\begin{tabular}{ccc}
$\begin{array}{c}\text { Business } \\
\text { Function }\end{array}$ & Business Service & Business Process \\
\hline Pemasaran & Pengelolaan feedback & Evaluasi kritik dan saran \\
\hline
\end{tabular}

TABEL 4c Business Service / Functional / Process Catalog Distribusi

\begin{tabular}{ccc}
\hline $\begin{array}{c}\text { Business } \\
\text { Function }\end{array}$ & Business Service & Business Process \\
\hline Distribusi & $\begin{array}{c}\text { Pengelolaan distribusi } \\
\text { produk }\end{array}$ & Penjualan via website \\
\cline { 2 - 2 } & & Penjualan via marketplace \\
\cline { 2 - 2 } & & Penjualan offline \\
\hline
\end{tabular}


TABEL 4d Business Service / Functional / Process Catalog Pengadaan

\begin{tabular}{ccc}
\hline $\begin{array}{c}\text { Business } \\
\text { Function }\end{array}$ & Business Service & Business Process \\
\hline Pengadaan & Pengelolaan vendor & Seleksi vendor \\
\cline { 2 - 3 } & & Penilaian vendor \\
\cline { 2 - 3 } & Pengadaan bahan dan alat & Pembelian bahan \\
\cline { 2 - 2 } & & Pembelian alat \\
\hline
\end{tabular}

TABEL 4e Business Service / Functional / Process Catalog Keuangan

\begin{tabular}{ccc} 
Business & Business Service & Business Process \\
\hline Keuangan & Pengelolaan keuangan & Pencatatan penjualan via website \\
\cline { 2 - 2 } & & $\begin{array}{c}\text { Pencatatan penjualan via } \\
\text { marketplace }\end{array}$ \\
\cline { 2 - 2 } & & Pencatatan penjualan offline \\
\cline { 2 - 2 } & & Pencatatan penjualan via media \\
& \\
& \\
& \\
&
\end{tabular}

Kemudian, Application Architecture menjelaskan perancangan aplikasi, hubungan aplikasi dan data serta kaitannya dengan proses bisnis yang ada pada UMKM Makanan Oleh-Oleh. Salah satu artefak yang dihasilkan yaitu Application Communication Diagram. Artefak ini menggambarkan hubungan antar aplikasi. GAMBAR 2 dibawah ini merupakan hubungan antar aplikasi pada UMKM Makanan Oleh-Oleh.

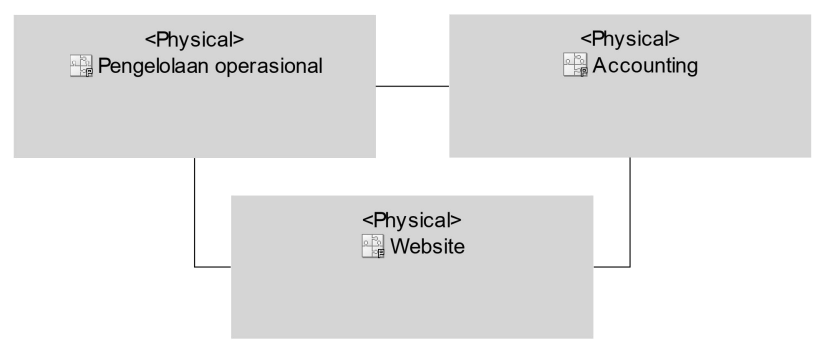

GAMBAR 2 Application Communication Diagram

Ket. $\square$ : Target

: Improvement

\section{4) Information System Architecture}

Fase ketiga dari TOGAF ADM yaitu fase Information System Architecture. Fase ini dibagi menjadi dua yaitu Data Architecture dan Application Architecture. Data Architecture mendefinisikan datadata yang digunakan saat ini dan data-data yang dibutuhkan pada masa mendatang. Pada Data Architecture dihasilkan beberapa artefak. Salah satunya yaitu Application / data matrix yang menggambarkan hubungan antar aplikasi dan entitas data. Pada TABEL 5 merupakan Application / data matrix UMKM Makanan Oleh-Oleh.

TABEL 5 Application Data Matrix

\begin{tabular}{ccc}
\hline Logical Application Component & Data Entity & Data Entity Type \\
\hline Pengelolaan Operasional & Faktur & Transactional Data \\
\cline { 2 - 3 } & Produk & Master Data \\
\cline { 2 - 3 } & Pelanggan & Transactional Data \\
\cline { 2 - 3 } & Bahan & Master Data \\
\cline { 2 - 3 } & Alat & Master Data \\
\cline { 2 - 3 } & Invoice & Transactional Data \\
\hline PO & Transactional Data \\
\cline { 2 - 3 } & Feedback & Transactional Data \\
\hline Vendor & Master Data \\
\hline Detail produk & Transactional Data \\
\hline Pegawai & Master Data \\
\cline { 2 - 3 } & Pembelian & Transactional Data \\
\cline { 2 - 3 } & Penjualan & Transactional Data \\
\cline { 2 - 3 } & User Management & Master Data \\
\cline { 2 - 3 } & Status feedback & Transactional Data \\
\cline { 2 - 3 } & Laporan & Transactional Data \\
\hline
\end{tabular}

Ket. : Target

\section{5) Technology Architecture}

Technology Architecture merupakan fase ke empat pada TOGAF ADM. Fase ini mendefinisikan teknologi yang akan dibuat pada sebuah proyek untuk mendukung visi arsitektur. Komponen utama technology architecture yaitu hardware, software, dan infrastruktur jaringan. Salah satu artefak yang dihasilkan pada fase ini yaitu Environments and locations diagram. Enviroments and Locations Diagram menggambarkan lokasi penggunaan aplikasi dan teknologi dan menggambarkan keterkaitan antara aplikasi dengan teknologi yang digunakan oleh UMKM. Pada GAMBAR 3 merupakan Environments and Locations Diagram pada UMKM Makanan OlehOleh.

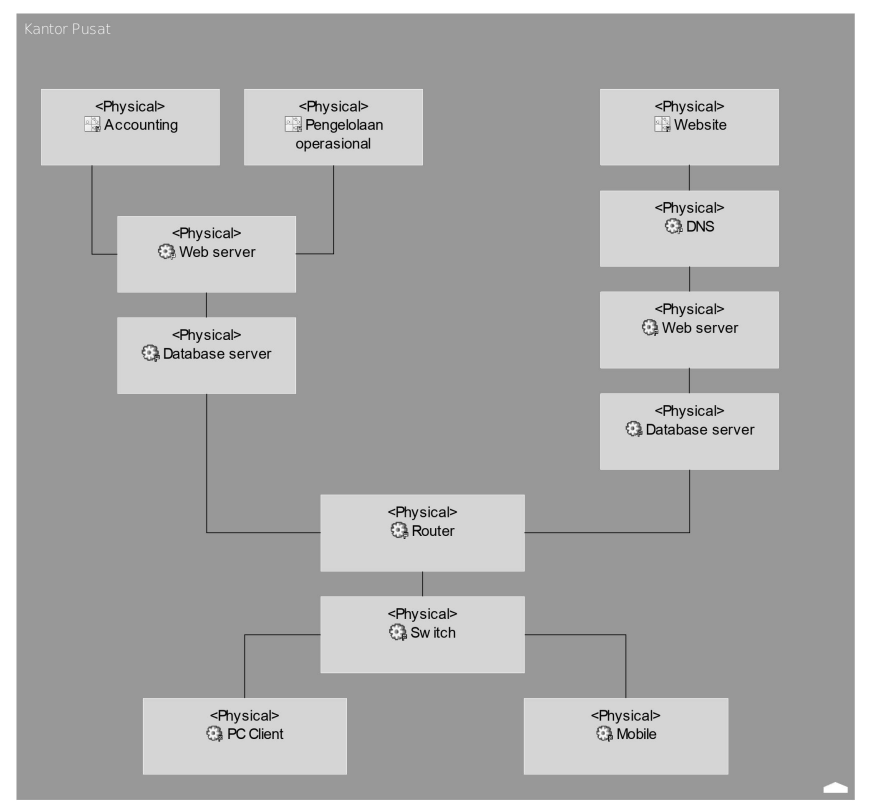

GAMBAR 3 Environments and Locations Diagram 


\section{6) EA Blueprint Company Specific}

EA blueprint yang dihasilkan sebagai acuan untuk UMKM Makanan Oleh-Oleh digambarkan pada GAMBAR 4.

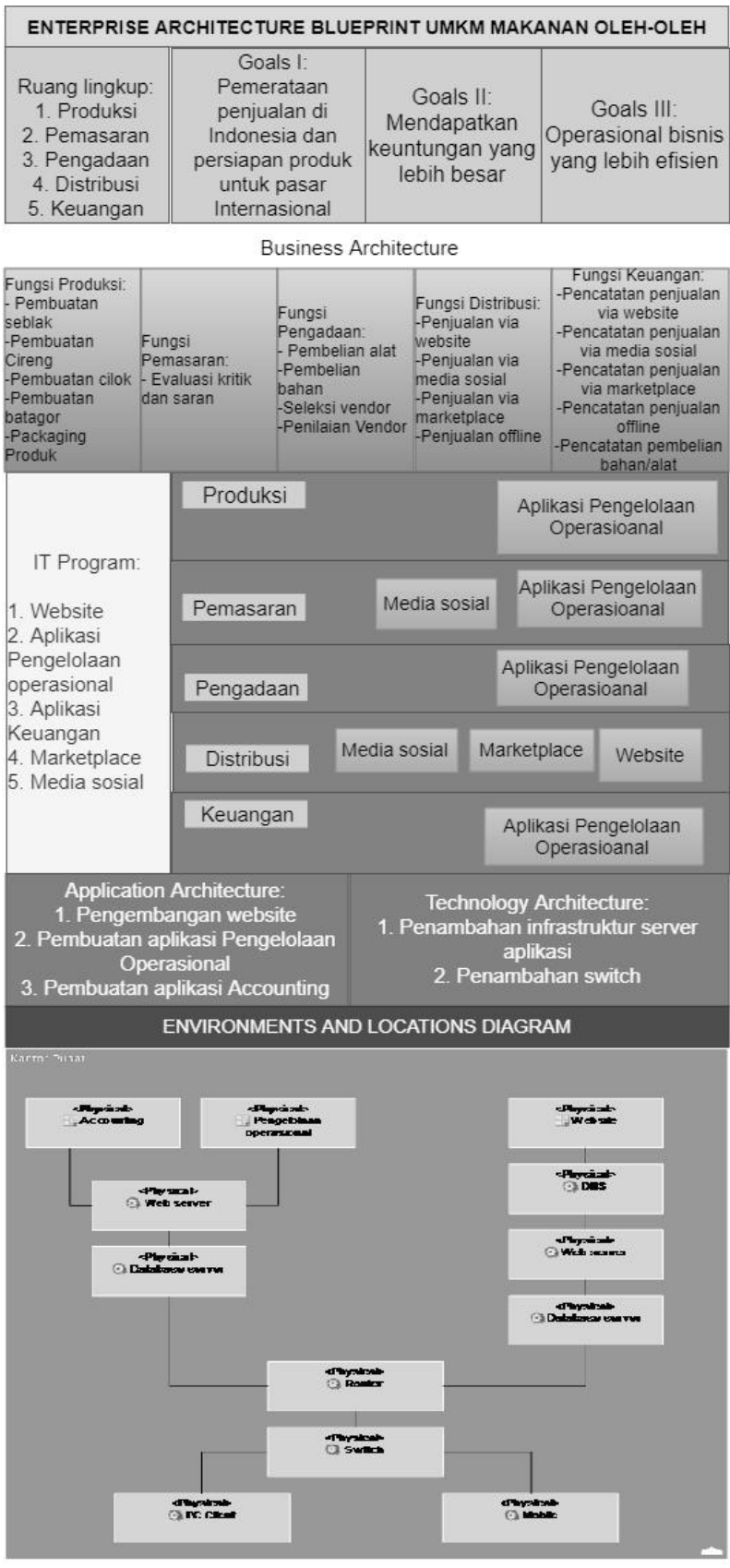

GAMBAR 4 EA Blueprint Company Specific

\section{KESIMPULAN}

UMKM perlu diterapkan Enterprise Architecture (EA) untuk membantu mencapai visinya, dalam kasus ini yaitu mencapai transformasi digital. Hal ini dikarenakan EA dapat menyelaraskan sisi bisnis yang ada dengan IT. Perancangan Enterprise Architecture pada penelitian ini menghasilkan EA blueprint company specific. Blueprint ini akan menjadi acuan UMKM Makanan Oleh-Oleh untuk mencapai transformasi digital. Ruang lingkup pada blueprint ini yaitu fungsi produksi, pemasaran, pengadaan, distribusi, dan keuangan. Tujuan UMKM Makanan Oleh-Oleh yaitu mencapai pemerataan penjualan di Indonesia dan mempersiapkan produk untuk penjualan ke luar negeri. Untuk itu, UMKM Makanan Oleh-Oleh perlu memiliki aplikasi yang dapat mengelola vendor, penjualan, feedback yang masuk, inventory, dan stock produk serta memiliki aplikasi pengelolaan keuangan untuk mendukung tujuan. Kemudian UMKM Makanan Oleh-Oleh perlu melakukan pengembangan website dan penambahan kerjasama dengan marketplace. UMKM Makanan OlehOleh juga memiliki target teknologi yaitu penambahan server aplikasi dan penambahan infrastruktur pendukung jaringan yang diperlukan. Hal ini menggambarkan bahwa UMKM dapat diterapkan sebuah Enterprise Architecture dengan mendefinisikan terlebih dahulu klasifikasi UMKM sehingga perancangan disesuaikan dengan klasifikasi dan kebutuhan UMKM.

\section{DAFTAR PUSTAKA}

[1] T. Aurora Lubis, "Pemanfaatan Teknologi Informasi pada Usaha Mikro Kecil dan Menengah di Kota Jambi," J. Perspekt. Pembiayaan dan Pembang. Drh., vol. 3, no. 3, pp. 2338-4603, 2016.

[2] K. Schwertner, "Digital transformation of business," Trakia J. Sci., vol. 15, no. Suppl.1, pp. 388-393, 2017.

[3] The Open Group, Open Group Standard TOGAF Version 9.1, vol. 18, no. 17. 2011.

[4] A. Grönlund, "It' s the Economy Stupid," Int. J. Public Inf. Syst., vol. 2, pp. 61-75, 2009.

[5] Dwipriyoko, E. Literature Review on New Generation Cooperative Enterprise Architecture. JURNAL TIARSIE, Vol.14, 51-56, 2017

[6] Dwipriyoko, E. Perancangan Arsitektur Aplikasi Open Source untuk Koperasi Generasi Baru, Studi Kasus Koperasi Terbaik Malaysia. SNIA 2017 UNJANI, Computer Crime and Digital Evidence, 3, 145-150, 2017 
[7] D. Jacobs and P. Kotzé, "Enterprise architecture for small and medium enterprise growth," $A d v$. Enterp., pp. 61-75, 2011.

[8] R. Alm and M. Wißotzki, "TOGAF adaption for small and medium enterprises," Lect. Notes Bus. Inf. Process., vol. 160, pp. 112-123, 2013.

[9] LPP Indonesia, Profil Bisnis Usaha Mikro Kecil dan Menengah. 2014.

[10] Dwipriyoko, E. New Generation Cooperative Financial Mathematical Model Preliminary Concept. Journal of Engineering and Applied Sciences, Vol.12, No.18, 4590-4594, 2017 